\title{
Oligonucleotide Linked to Human Gammaglobulin Specifically Diminishes Anti-DNA Antibody Formation in Cultured Lymphoid Cells from Patients with Systemic Lupus Erythematosus
}

\author{
Yves Borel and Halina Borel \\ The Center for Blood Research and the Department of Pediatrics, Harvard Medical School, Boston, Massachusetts 02115
}

\begin{abstract}
In vitro studies were undertaken to determine whether the level of anti-DNA antibody can be modulated in humans with systemic lupus erythematosus (SLE). DNA fragments of different sizes, i.e., oligonucleotide $\left(\mathbf{N}_{20-30}\right)$ or oligonucleotide $\left(\mathbf{N}_{10-100}\right)$, were covalently linked either to human gammaglobulin (HGG) and used as tolerogens or to keyhole limpet hemocyanin and used as immunogens. Experiments were done to determine whether such tolerogens specifically diminish antibodies to denatured DNA, native DNA, or both. PBL were obtained from 87 patients with SLE, 55 of whom spontaneously produced anti-DNA antibodies in vitro. Furthermore, of these 55 test subjects 23 made anti-DNA antibodies in response to antigen challenge in vitro. Exposure of PBL to tolerogenic oligonucleotide-HGG reduced spontaneous antibody formation in 34 of the 55 patients' PBL and abrogated the in vitro-induced response in all instances. The suppression was tolerogen specific. In some SLE patients lymphoid cells were suppressed by both ( $\left.\mathbf{N}_{10-100}\right)$-HGG and $\left(\mathrm{N}_{20-30}\right)$-HGG, while in others lymphoid cells were suppressed by only one. Longitudinal studies of spontaneous antibody production showed that the same tolerogens consistently reduced anti-DNA antibody formation in lymphoid cells of 12 patients on several occasions over a 2-yr interval, but in 8 others the results were either variable or inconsistent. In contrast, tolerogens consistently abrogated the antigen-induced response in all 23 patients' PBL. These results obtained in humans in vitro suggest that the principle of carrier-determined tolerance could be applied as a specific therapy for SLE in vivo.
\end{abstract}

\section{Introduction}

Systemic lupus erythematosus (SLE) is the autoimmune disease par excellence because many autoantibodies to self-antigens, including nucleic acid, are formed (1-3). Whether DNA is an antigenic stimulus in SLE has been a subject of controversy $(4,5)$, not only because some anti-DNA antibodies cross-react with antigens irrelevant to DNA, but also because other antigens such as cardiolipin and Klebsiella may give rise to antibodies cross-reacting with DNA (6-13). Likewise, the presence of anti-DNA antibodies may or may not correlate

Address reprint requests to Dr. Yves Borel, The Center for Blood Research, 800 Huntington Avenue, Boston, MA 12115.

Received for publication 19 January 1988 and in revised form 11 July 1988.

J. Clin. Invest.

(C) The American Society for Clinical Investigation, Inc. 0021-9738/88/12/1901/07 \$2.00

Volume 82, December 1988, 1901-1907 with disease activity (14-17). Despite these paradoxes, antinucleic acid antibodies in general, and anti-native DNA (nDNA $)^{1}$ in particular, are still the hallmark of $\operatorname{SLE}(18,19)$. Moreover, antibodies to DNA have been clearly shown to play a role in the mechanism of tissue injury both in murine and human SLE $(20,21)$. Consequently, specific suppression of anti-DNA antibody by the induction of immunologic tolerance to DNA may have therapeutic value. One way to test this idea is to determine whether conjugates of DNA fragments (oligonucleotides) covalently linked to the self-carrier human gammaglobulin (HGG) specifically modulate anti-DNA antibodies in vitro. The data suggest that both spontaneous and antigen-induced anti-DNA antibodies produced by cultured lymphoid cells from SLE patients can be specifically diminished by oligonucleotides covalently bound to HGG.

\section{Methods}

Preparation of antigens and tolerogens. Calf thymus DNA was purchased from Worthington Biochemical Corp. (Freehold, NJ). It was further purified to remove RNA and protein, and then digested with DNase as previously described (22). Total DNA digest was fractionated by chromatography on Ultragel (Pharmacia Fine Chemicals, Piscataway, NJ) as seen in Fig. 1, and fractions were collected. Two sizes of DNA fragments containing either $10-100\left(\mathrm{~N}_{10-100}\right)$ or $20-30\left(\mathrm{~N}_{20-30}\right)$ bp were obtained. The size of the fragments was determined by PAGE. These oligonucleotide fragments were linked to a protein carrier using glutaraldehyde as a linking agent in a two-step procedure as previously described (23). Two types of immunogens were prepared: total DNA digest $\left(\mathrm{N}_{10-100}\right)$ and oligonucleotides $\left(\mathrm{N}_{20-30}\right)$ linked to keyhole limpet hemocyanin (KLH). Likewise, two types of tolerogens were prepared: $\left(\mathrm{N}_{10-100}\right)$ and $\left(\mathrm{N}_{20-30}\right)$ linked to $\mathrm{HGG}$ as previously described (22). HGG suitable for intravenous therapy was obtained either from Immuno AG or Sandoz Ltd. (Basel, Switzerland) (Sandoglobulin). For specificity controls, we used similar DNA fragments and HGG that were not covalently bound together. In addition, in some instances we used tetranucleoside linked to HGG, prepared as previously described (24), or the immunogen (oligonucleotide) linked to $\mathrm{KLH}$.

Patient population. 87 people with SLE were studied. 79 were patients of Dr. A. Steinberg at the Arthritis Branch of the National Institute of Arthritis, Diabetes, and Digestive and Kidney Diseases (Bethesda, MD) and 8 were from the Children's Hospital in Boston. All SLE patients satisfied the diagnostic criteria of the American Rheumatism Association (25). Clinical activity was assessed by the physicians on the basis of signs and symptoms (rash, serositis, arthritis, central nervous system disease, and renal disease) at the time of blood drawing. No attempt was made to separate patients into subsets of

1. Abbreviations used in this paper: CM, a tissue culture medium containing RPMI 1640 supplemented with 10\% fetal bovine serum, 25 mM Hepes buffer, $200 \mathrm{mM}$ glutamine, $1 \%$ penicillin/streptomycin, and $5 \times 10^{-5} \mathrm{M}$ mercaptoethanol; d-DNA, denatured DNA; HGG, human gammaglobulin; KLH, keyhole limpet hemocyanin; n-DNA, native DNA. 


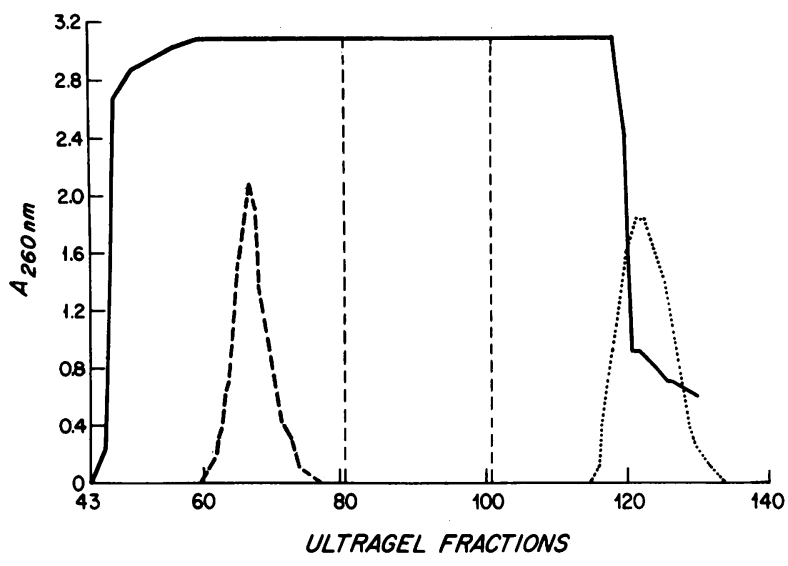

Figure 1. Chromatography on ultragel of total DNA digest to obtain oligonucleotides. Ultragel fractions (16 drops each) 43-120 represent the total DNA digest $\left(\mathrm{N}_{10-100}\right)$. Fractions 80-101 represent oligonucleotide $\left(\mathrm{N}_{20-30}\right) .---, \mathrm{IgG} ; \cdots$, a mononucleotide (both used as markers).

clinical activity. Patients lacking these symptoms or signs were categorized as inactive. $65 \%$ were active and $35 \%$ inactive. $90 \%$ of patients with active disease and $75 \%$ of patients with inactive disease were receiving corticosteroids. The dose of prednisone never exceeded 1 $\mathrm{mg} / \mathrm{kg}$. None of the patients was receiving immunosuppressive drugs such as cytoxan or azathioprine. Corticosteroid was not given on the day blood was drawn. In addition, $24 \mathrm{~h}$ elapsed between blood withdrawal, washing, and adding tolerogen to culture medium.

Cultured lymphoid cells from SLE patients. Peripheral blood lymphoid cells were isolated by Ficoll-Hypaque (Pharmacia Fine Chemicals) density centrifugation. Cell suspensions were cultured at a final concentration of $5 \times 10^{6}$ cells $/ \mathrm{ml}$ in flat-bottom microtiter plates (Becton-Dickinson Co., Falcon Labware Div., Rutherford, NJ). 1 $\times 10^{6}$ cells were used per culture because this was shown to give an optimum immune response to $1 \mu \mathrm{g}$ of antigen (23). The tissue culture medium was RPMI 1640 supplemented with $10 \%$ fetal bovine serum, $25 \mathrm{mM}$ Hepes buffer, $200 \mathrm{mM}$ glutamine, $1 \%$ penicillin/streptomycin, and $5 \times 10^{-5} \mathrm{M}$ mercaptoethanol. This preparation is referred to hereafter as $\mathrm{CM}$. Cultures were set up in triplicate and maintained at $37^{\circ} \mathrm{C}$ in a humid atmosphere of $5 \% \mathrm{CO}_{2}$ in air.

Experimental protocol. Tolerogen and antigen solutions were prepared by diluting stock of either $\left(\mathrm{N}_{10-100}\right)$ conjugate or $\left(\mathrm{N}_{20-30}\right)$ conju-

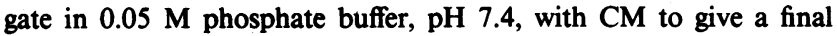
concentration of $5-50 \mu \mathrm{g} / \mathrm{ml} .200 \mu \mathrm{l}$ of the final dilutions of these preparations was added to each culture. Tolerogens were added in the first culture. As controls, we used a mixture of unbound DNA fragments or oligonucleotides with the same concentration of HGG (control mixture) or each component alone (i.e., oligonucleotide or HGG). For specificity controls we used either nucleosides linked to HGG or oligonucleotides linked to KLH. We found that a 10-24-h incubation with tolerogens was sufficient to decrease spontaneous antibody formation and that a 2-4-d incubation gave similar results. Therefore, an 18-h incubation was chosen, after which the cells were washed three times and resuspended in fresh medium for $4 \mathrm{~d}$. During this 4-d incubation, antigen was either added as described above, or not added, depending on whether either spontaneous or antigen-induced antibody formation was being measured. The cells were again washed three times and resuspended in fresh medium for $6 \mathrm{~d}$. Cells were harvested and antibody was assayed in the culture supernatant.

Solid-phase RIA. Polyvinylchloride microtiter plates (Dynatech Laboratories, Inc., Arlington, VA) were coated with $0.1 \%$ protamine sulfate in distilled water for $90 \mathrm{~min}$, rinsed thoroughly with distilled water, then coated with either $50 \mu \mathrm{g} / \mathrm{ml} \mathrm{n}$-DNA or $50 \mu \mathrm{g} / \mathrm{ml}$ heat-denatured DNA (d-DNA). Ovalbumin was used at the same concentration as an irrelevant target antigen. All antigens were allowed to stand at $4^{\circ} \mathrm{C}$ overnight for maximal coating. The coated plates were rinsed three times with a washing solution of $0.25 \%$ fetal bovine serum and $0.05 \%$ Tween 20 in PBS, pH 7.4.

A blocking solution of $1 \%$ BSA and 3\% fetal bovine serum in PBS was then added to all wells for $1 \mathrm{~h}$ at room temperature. The plate was again washed three times with washing solution, then samples of the culture supernatants were added and allowed to incubate at $37^{\circ} \mathrm{C}$ for $90 \mathrm{~min}$. Again the plate was washed three times before being developed with ${ }^{125} \mathrm{I}-\left(\mathrm{Fab}^{\prime}\right)_{2}$ adjusted to $10^{6} \mathrm{cpm} / \mathrm{ml}(100 \mu \mathrm{l} /$ well $)$ in the blocking solution above. $\left(\mathrm{Fab}^{\prime}\right)_{2}$ was obtained by pepsin digestion of rabbit anti-human Ig which recognizes both IgG and IgM. In some instances, to detect class-specific antibody, ${ }^{125} \mathrm{I}$-(Fab) ${ }_{2}$ goat anti-human reactive with IgM or IgG (New England Nuclear Boston, MA) were used. Plates were developed for $90 \mathrm{~min}$ at room temperature, washed as above with washing buffer, and then dried. The plates were cut with scissors and each well was counted for bound radioactivity in a gamma counter. Antibodies to n-DNA, d-DNA, or ovalbumin secreted into the culture supernatant were assayed in triplicate. Background values determined either by the antigen with $\mathrm{CM}$ or the irrelevant antigen ovalbumin were $<600 \pm 30 \mathrm{cpm}$, and were subtracted from the experimental values. The data expressed as $\mathrm{cpm}$ /culture are the net geometric means of three separate cultures above background. A two-tailed $t$ test was used to analyze the significance of the data. For spontaneous antibody production after preincubation with tolerogen, a 30\% reduction $(>2$ SD compared with controls) was chosen as significant.

\section{Results}

Production of either spontaneous or antigen-induced antiDNA antibody in vitro. PBL from 87 people with SLE were tested for spontaneous production of anti-DNA antibody in vitro. 63\% (55 of 87) formed antibody spontaneously. In 107 experiments from these 55 patients antibody to both n-DNA and d-DNA was produced in $45 \%$ of the cases, whereas antibody to either n-DNA or d-DNA alone was formed in 20 and $15 \%$ of the cases, respectively. None formed antibody to ovalbumin. The range of the spontaneous response expressed as net cpm/culture 2 SD above background) varied as follows: $1-150,8 \%$; 150-300, 22\%; 300-1,000, 22\%; 1,000-3,000, $32 \%$; and $3,000-15,000,16 \%$. The class was examined in 50 experiments. Of those, we found that 17 made IgM only, 21 made both IgM or IgG, and 12 made IgG antibody only.

Previously we had shown that one can elicit anti-DNA antibody in vitro by challenging PBL from SLE patients with DNA fragments covalently linked to KLH (23). All 87 patients' PBL were challenged with antigen in vitro. We found that 23 patients' PBL responded by making anti-DNA antibody. All patients producing antigen-induced antibody also formed spontaneous antibody. In all instances, antibodies to both n-DNA or d-DNA were assayed. Six patients' PBL were tested more than once. Of the 30 experiments from 23 patients, 11 gave a response to n-DNA only, 10 to d-DNA only, and 9 to both antigens as seen in Table I. In 24 cases where the class of the immune response was determined, 12 were IgM, 9 IgG, and 3 both IgM and IgG.

Specific reduction of spontaneous anti-DNA antibody formation by oligonucleotide-HGG tolerogen. Initially, we determined the dose of tolerogen necessary to influence spontaneous anti-DNA antibody formation. Fig. 2 shows two representative experiments obtained from PBL of two SLE patients. In both instances there was a $50 \%$ reduction of antibody produced to either n-DNA or d-DNA, induced by a dose of 1 $\mu \mathrm{g} /$ culture of tolerogen. Neither a lower dose $(0.1 \mu \mathrm{g})$ nor higher doses ( $3 \mu \mathrm{g}$ or $10 \mu \mathrm{g}$ ) appeared to be as effective, sug- 
Table I.

\begin{tabular}{|c|c|c|c|c|}
\hline \multirow{2}{*}{$\begin{array}{c}\text { No. of } \\
\text { experiments }\end{array}$} & \multicolumn{2}{|c|}{ Spontaneous antibody } & \multicolumn{2}{|c|}{$\begin{array}{l}\text { Antigen-induced } \\
\text { antibody responses }\end{array}$} \\
\hline & n-DNA & d-DNA & n-DNA & d-DNA \\
\hline 1 & 1,773 & 1,200 & 3,873 & 15,366 \\
\hline 2 & 16,725 & - & 33,543 & - \\
\hline 3 & 261 & 480 & 744 & 2,481 \\
\hline 4 & 60 & - & 810 & - \\
\hline 5 & - & 279 & - & 1,593 \\
\hline 6 & 3,312 & - & 7,398 & - \\
\hline 7 & 2,001 & - & 6,810 & - \\
\hline 8 & 3,246 & - & 8,700 & - \\
\hline 9 & 4,188 & 4,160 & 10,518 & 10,509 \\
\hline 10 & 1,526 & 1,428 & 2,500 & 2,280 \\
\hline 11 & 711 & - & 1,338 & - \\
\hline 12 & - & 417 & - & 870 \\
\hline 13 & 538 & - & 1,197 & - \\
\hline 14 & - & 1,980 & - & 3,856 \\
\hline 15 & 462 & - & 2,853 & - \\
\hline 16 & - & 1,278 & - & 2,184 \\
\hline 17 & - & 1,656 & - & 5,265 \\
\hline 18 & 300 & 296 & 900 & 856 \\
\hline 19 & 189 & - & 414 & - \\
\hline 20 & - & 256 & - & 516 \\
\hline 21 & 282 & 321 & 777 & 5,571 \\
\hline 22 & 189 & 240 & 654 & 2,232 \\
\hline 23 & 156 & 285 & 633 & 783 \\
\hline 24 & 330 & 519 & 2,478 & 3,618 \\
\hline 25 & - & 492 & - & 996 \\
\hline 26 & - & 570 & - & 1,488 \\
\hline 27 & - & 2,502 & - & 6,666 \\
\hline 28 & 117 & - & 957 & - \\
\hline 29 & - & 165 & - & 510 \\
\hline 30 & 672 & - & 1,755 & - \\
\hline
\end{tabular}

Each figure represents mean cpm/culture per triplicate above background. Each line illustrates the antigen-induced response above the spontaneous immune response.

gesting that the observed reduction was not due to passive absorption of preformed antibody by tolerogen.

Since two different sizes of DNA fragments were used to construct tolerogens (either [ $\left.\mathrm{N}_{10-100}\right]-\mathrm{HGG}$ or [ $\left.\mathrm{N}_{20-30}\right]-\mathrm{HGG}$ ), we determined whether either one or both conjugates could diminish anti-DNA spontaneously formed in vitro. The results are summarized in Table II. Antibody was reduced by one or both types of tolerogen in 34 of 55 patients' PBL (60\%) that produced anti-DNA spontaneously. The specificity of the reduction of antibody spontaneously produced was examined in a number of experiments. A typical example is shown in Fig. 3. DNA fragments must be covalently linked to the carrier (HGG) for the conjugate to be tolerogenic. In contrast, nucleoside linked to HGG failed to affect the response to d-DNA. The specificity was further studied in a number of instances in which one type of tolerogen (either $\left[\mathrm{N}_{10-100}\right]-\mathrm{HGG}$ or $\left[\mathrm{N}_{20-30}\right]$ HGG) diminished the spontaneous response. This was done either by linking the same DNA fragment to an immunogenic carrier protein KLH or by using a DNA fragment of a different size linked to HGG. One example of each is given in Fig. 4.

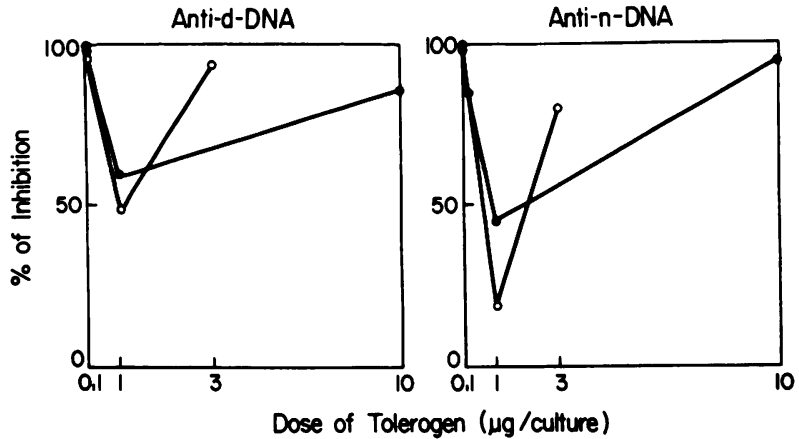

Figure 2. Diminution of spontaneous anti-DNA antibody production by tolerogen. Percent of inhibition as compared with spontaneous antibody formation (100\% control). 0 , each line represents the result obtained from one SLE patient; $\bullet$, cultured lymphocytes. Note that at high doses there was practically no inhibition, ruling out a nonspecific binding of preformed antibody as the cause of the reduction of antibody production.

Depending on the type of immune response produced, the formation of antibody to either d-DNA, n-DNA, or both can be affected by tolerogen as seen in Fig. 4. Exp. 1 shows a representative experiment in which the production of anti-dDNA was diminished by both types of tolerogens, whereas Exp. 2 shows anti-n-DNA reduced by oligonucleotide $\left(\mathrm{N}_{20-30}\right)$-HGG. Since some SLE patients' PBL spontaneously produced IgG class antibody to either d-DNA or n-DNA, we examined whether we could diminish this class of antibody. Exp. 3 shows a representative experiment in which $\left(\mathrm{N}_{10-100}\right)$ HGG suppressed IgG to both anti-d-DNA and anti-n-DNA. It should be emphasized (as seen in Table II) that either one or both oligonucleotides' gammaglobulin conjugates failed to be tolerogenic in $\sim 40 \%$ of the cases. The reason could be either that $\mathrm{T}$ and/or B cells of this particular patient's PBL were resistant to tolerance induction, or that specificity of the antinucleic acid antibody produced did not correspond to the size of the DNA fragment used to construct a tolerogen. Therefore, it was critical to test the same tolerogenic conjugate on several occasions for the same patient's PBL.

Longitudinal study for the diminution of spontaneous antibody formation. There is considerable variability in the pro-

Table II. Summary of Data Showing Diminution of Spontaneous Anti-DNA Antibody by Tolerogens

\begin{tabular}{cc}
\hline Tolerogens used & $\begin{array}{c}\text { No. of } \\
\text { experiments }\end{array}$ \\
\hline $\begin{array}{c}\left(\mathrm{N}_{20-30}\right) \text {-HGG } \\
\text { and }\end{array}$ & \\
$\left(\mathrm{N}_{10-100}\right)-\mathrm{HGG}$ & 9 \\
$\left(\mathrm{~N}_{20-30}\right)-\mathrm{HGG}$ & \\
$\left(\mathrm{N}_{10-100}\right)-\mathrm{HGG}$ & 11 \\
Total & 14 \\
\end{tabular}

This table represents the composite results of the effect of tolerogens on the response in all 55 patients producing anti-DNA antibody spontaneously. Thus, in 34 of 55 cases $(61 \%)$ tolerogens were effective. Reduction of spontaneous anti-DNA antibody formation by tolerogens means $<30 \%$ of controls as indicated in Methods. 


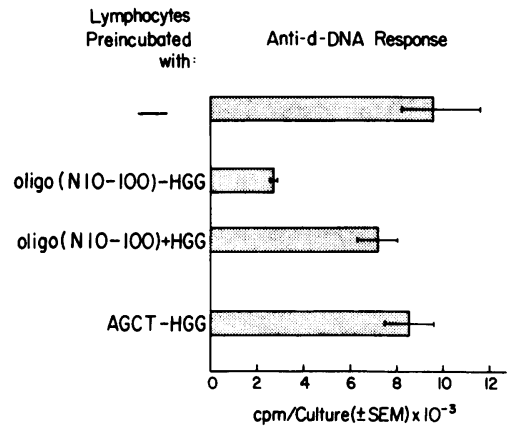

covalently bound to HGG (control mixture). Group 4 was preincubated with tetranucleoside (AGCT) linked to HGG. Each bar represents the geometric mean of triplicate cultures \pm SEM.

duction of spontaneous antibody by PBL not only among patients but also within each patient. During a 2-yr interval we had the opportunity to study 20 patients' PBL. The results are summarized in Table III. They fall into two broad categories: in a population of 12 patients' PBL we found that the suppression of anti-DNA antibody formation was both consistent and specific for the type of tolerogens used; on the other hand, in a population of eight SLE patients' PBL there is variability both in the ability of tolerogens to diminish antibody formation and in the formation and specificity of antibody produced.

Suppression of antigen-induced antibody production. Next we determined whether pretreatment with tolerogen would influence the immune response after antigen challenge in
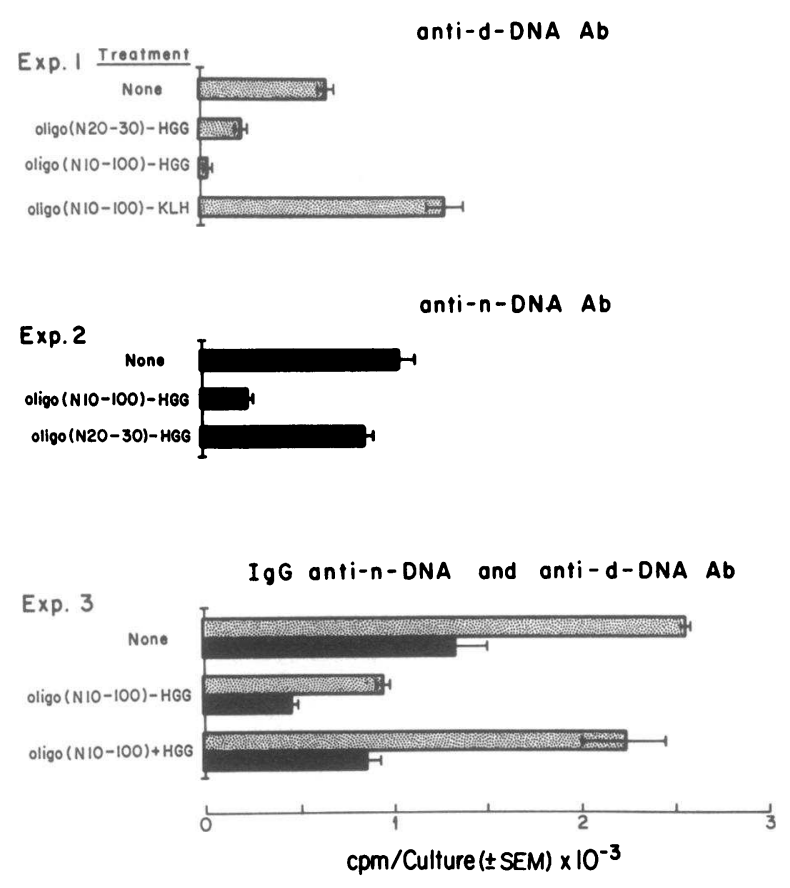

Figure 4. Diminution of spontaneous anti-DNA antibody by tolerogens. Three examples of reduction of antibody formation by tolerogen. In the first experiment both tolerogens in contrast to the antigen were tolerogenic. The second and third experiments illustrate that either oligonucleotide $\left(\mathrm{N}_{20-30}\right)$-HGG or oligonucleotide $\left(\mathrm{N}_{10-100}\right)-\mathrm{HGG}$ can be tolerogenic. Each experiment was done with a single SLE patient's cultured lymphocytes. $m$, antibody to d-DNA; $\square$, antibody to n-DNA.
Table III. Longitudinal Study of the Diminution of Spontaneous Anti-DNA Antibody by Tolerogens

\begin{tabular}{lccc}
\hline \multirow{2}{*}{$\begin{array}{c}\text { No. of } \\
\text { patients' PBL }\end{array}$} & \multicolumn{2}{c}{ Tolerogens } & $\begin{array}{c}\text { No. of } \\
\text { times tested }\end{array}$ \\
\cline { 2 - 4 } Group I & $\left(\mathbf{N}_{10-100}\right)$-HGG & $\left(\mathrm{N}_{20-30}\right)-\mathrm{HGG}$ & \\
5 & & & 5 \\
5 & + & + & 3 \\
2 & - & - & 3 \\
Group II & + & + & \\
2 & + & - & 2 \\
& ND & No Ab & 1 \\
& No Ab & + & 3 \\
4 & - & - & 5 \\
& + & - & 1 \\
2 & - & - & 3 \\
& + & - & 2 \\
& - & & 5 \\
\hline
\end{tabular}

This table represents the number of times 20 patients' PBL were challenged with the same type of tolerogens during a 2-yr interval. This longitudinal study tested the consistency of tolerance induction by one or the other or both types of tolerogen in the same patient's PBL in the course of the disease. In Group I tolerogens consistently reduced anti-DNA antibody, whereas in Group II they did not. +, preincubation of cultured lymphocytes with tolerogen diminishes spontaneous antibody formation; - , no diminution as compared with control cultures not treated with tolerogen.

vitro. This was done not only because production of spontaneous antibody to DNA is both small and variable, but also to determine whether the tolerogen could influence a booster response elicited by exogenous antigen challenge in vitro. We tested PBL from all 23 patients responding to antigen challenge in vitro. Six patients' PBL were tested more than once. Regardless of the type of tolerogen or immunogen used, we found that the antigen-induced response was abrogated by preincubation with tolerogen in all instances except one. This case was tolerized and immunized by both types of tolerogens and immunogens. One tolerogen suppressed only the response elicited by the corresponding immunogen. Fig. 5 shows that $\left(\mathrm{N}_{20-30}\right)$-HGG abolished the response to the corresponding immunogen. In contrast, the other type of tolerogen failed to diminish the response to the corresponding immunogen. Thus, tolerance induction to n-DNA was tolerogen specific. In 23 of 30 cases the suppression was $95 \%$ and in 7 cases $57-95 \%$. Thus, of the 30 cases 7 were tolerized by $\left(\mathrm{N}_{20-30}\right)$-HGG before in vitro challenge with oligonucleotide $\left(\mathrm{N}_{20-30}\right)-\mathrm{KLH}$ and 18 were tolerized by $\left(\mathrm{N}_{10-100}\right)$-HGG before challenge with $\left(\mathrm{N}_{10-100}\right)-\mathrm{KLH}$. In four instances, different DNA fragments were used as either tolerogenic or immunogenic conjugates. Thus, three were tolerized by $\left(\mathrm{N}_{10-100}\right)$-HGG before challenge with $\left(\mathrm{N}_{20-30}\right)-\mathrm{KLH}$ and one was tolerized by $\left(\mathrm{N}_{20-30}\right)$-HGG before challenge with $\left(\mathrm{N}_{10-100}\right)-\mathrm{KLH}$. Fig. 6 illustrates two representative experiments in which the IgM anti-d-DNA and n-DNA were assayed. Pretreatment with $\left(\mathrm{N}_{10-100}\right)$-HGG abrogated the immune response to the corresponding antigen $\left(\mathrm{N}_{10-100)}-\mathrm{KLH}\right.$. In contrast, controls made of a mixture of oligonucleotide together with IgG failed to inhibit the response to the antigen. Both IgM and IgG response to native anti-DNA 

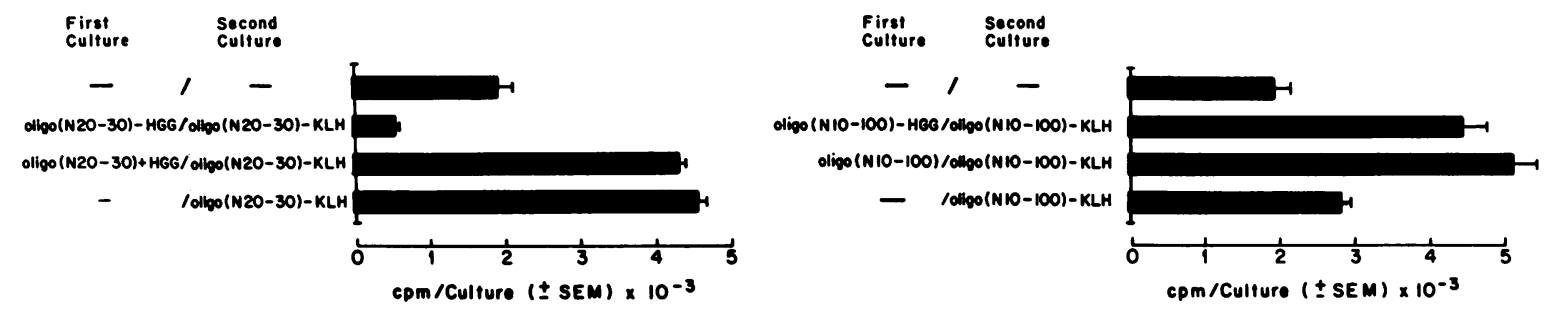

Figure 5. Specificity of the suppression of the antigen-induced response in a case tolerized and immunized by both types of compounds. Note that only oligonucleotide $\left(\mathrm{N}_{20-30}\right)$-HGG tolerized the immune response induced by the corresponding antigen.

antibody elicited by $\left(\mathrm{N}_{10-100}\right)$ linked to $\mathrm{KLH}$ can be suppressed by $\left(\mathrm{N}_{10-100}\right)$-HGG (Fig. 7 ).

Finally, in some experiments we observed that PBL preincubated with human gammaglobulin together with oligonucleotide (control mixture) resulted in either a decrease or increase of the immune response elicited by the immunogen. We examined the role of either the carrier (HGG) or the hapten (oligonucleotides) in producing this phenomenon. We found that in $15 \%$ of the cases HGG could decrease the response of the immunogen, although the suppression was less profound than the tolerogen (Fig. 8). In contrast, in 6 of 30 cases preincubation with oligonucleotide alone appears to prime the antigeninduced immune response (shown in Fig. 5, Exp. 1 and Fig. 7).

\section{Discussion}

The development of an antigen-specific immunotherapy for SLE has been hampered not by the ability to induce tolerance to nucleic acid antigen $(24,26)$, but by the inability to link fragments of DNA to protein carriers to accommodate the combining site of antinucleic acid antibodies made by the SLE patients $(22,27)$. We have previously shown that oligonucleotide linked to KLH is immunogenic (23). In this paper we have shown that similar DNA fragments linked to human gammaglobulin are tolerogenic, since either spontaneous or antigeninduced anti-d-DNA or anti-n-DNA can be specifically diminished by preincubation of cultured lymphoid cells with DNA fragments linked to HGG. These results obtained in humans in vitro extend earlier studies done in experimental animals in vivo in which tolerance was induced to small nucleic acid antigens such as nucleosides or nucleotides (24, 28, 29).

Spontaneous production of antibody to DNA was reduced by preincubation with tolerogen in $60 \%$ of the cases. In contrast, antigen-induced antibody production was abrogated in all cultures tested but one. Why is this so? First, the amount of spontaneous antibody formed is relatively small and the nature of the endogenous antigen, if any, that stimulates its production is still ill-defined. Second, since both B and T cells' (30) autoreactivity might account for the small amount of antibody spontaneously formed, polyclonal activation might be more resistant to tolerance induction than that induced by exogenous nucleic acid antigen challenge in vitro in which the specificities of tolerogen and immunogen are similar.

Clearly the diminution of spontaneous antibody to either d-DNA or n-DNA was tolerogen specific. Why the immune response in certain patients' PBL was suppressed by both types of tolerogens whereas others were tolerized by either tolerogen is unclear, since the large DNA fragments $\left(\mathrm{N}_{10-100}\right)$ contain the small fragments $\left(\mathrm{N}_{10-30}\right)$. It is known that SLE patients make antibody that recognizes either small or large DNA fragments $(27,31)$. It is conceivable that after covalent linkage of oligonucleotides of different sizes to the carrier molecule (HGG) the degree of conjugation and/or the spatial presentation of tolerogens might influence their binding to the receptor on lymphoid cells. Furthermore, there is variability in the specificity

IgM anti-d-DNA and anti-n-DNA $A b$

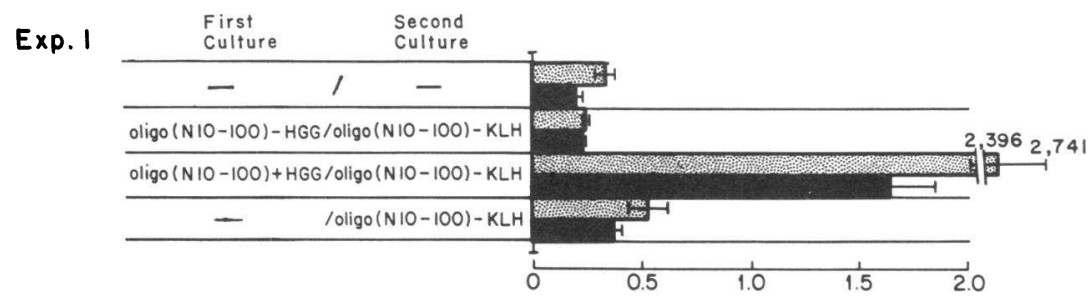

Exp. 2

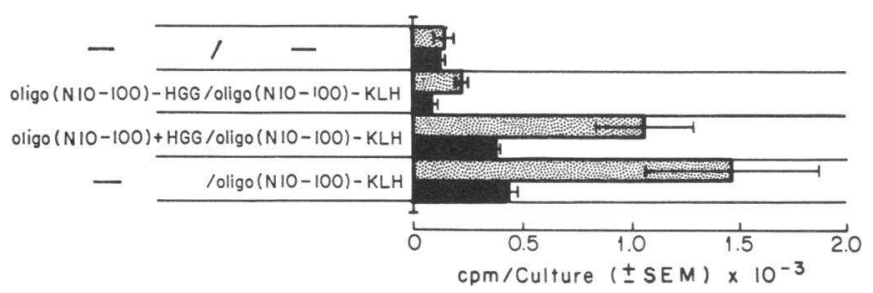

Figure 6. Suppression of antigen-induced antiDNA antibody. Two examples of the specific suppression of IgM anti-DNA antibody production by tolerogen before challenge with antigen in vitro. Note that in Exp. 1 the control mixture (DNA fragments together with HGG but not linked) had a priming effect on the antigen-induced response. $a$, anti-d-DNA; $\square$, anti-n-DNA. 


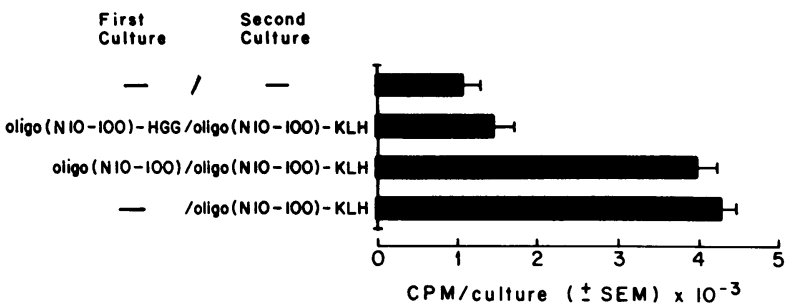

Figure 7. Suppression of IgG anti-n-DNA antibody by tolerogen.

of natural anti-DNA antibody production not only among patients' lymphoid cells but also at different times for the same patients' lymphoid cells. Therefore, it was important to test the same tolerogens in the same patients' PBL in the course of the disease. The results of such a longitudinal study showed that in 12 patients' PBL examined several times, the same tolerogens gave consistent results. Similar results were obtained for diminution of anti-DNA antibody elicited by antigen challenge in vitro. On the other hand, there is a group producing spontaneous antibody in which the results are either variable or inconsistent. Because in SLE the auto-antibodies to DNA are polyspecific (6) the variability of the results in some patients' PBL may also reflect the complexity of this issue.

It should be emphasized that both IgM and IgG antibodies to d-DNA or n-DNA formed either spontaneously or after an antigen-induced response in vitro were suppressed. Because high avidity IgG reacting with n-DNA and fixing complement not only causes tissue damage (32), but also correlates with disease activity $(14,19,33)$, the observation that $\operatorname{IgG}$ antibody to n-DNA can be reduced may have therapeutic value.

Other workers have proposed different therapeutic strategies to suppress anti-DNA antibodies in PBL of SLE patients in vitro. For example, either nucleic acid antigens or antiidiotypic antibodies to DNA have been covalently linked to immunotoxic drugs in an attempt to delete the clone of B cells producing anti-DNA antibody $(34,35)$. In murine models other investigators have also shown that nucleoside linked to dGL or DNA fragments linked to poly- $d$-lysine together with cyclophosphamide can suppress anti-DNA antibodies resulting in clinical improvement of murine lupus $(36,37)$. In this study, we have not examined the mechanism of tolerance in vitro, but in other human models involving haptens linked to HGG we have shown that not only B cells but also T cells are involved $(38,39)$. Clearly the tolerogenicity of the conjugate is

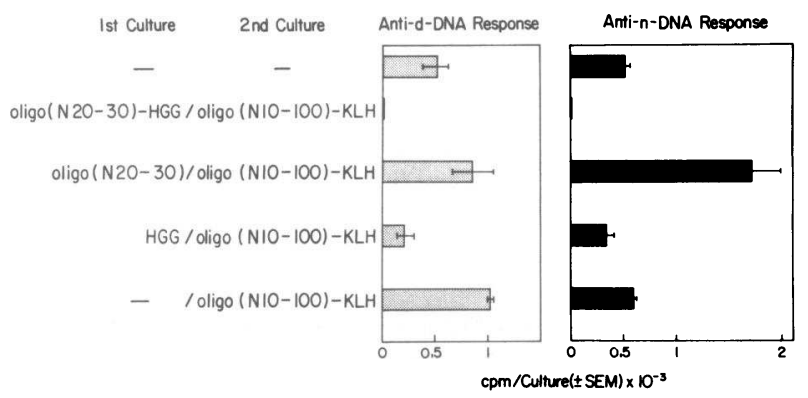

Figure 8. Effect of the carrier protein HGG alone on the diminution of antigen-induced anti-DNA antibody in vitro. Whereas HGG alone reduced antibody formation induced by antigen challenge in vitro, oligonucleotide alone appears to prime the antigen-induced response. determined by the carrier molecule HGG. Oligonucleotides have to be covalently linked to the carrier for the conjugate to be tolerogenic, since the mixture of oligonucleotide and HGG is ineffective. The observation that in some instances preincubation with HGG alone can diminish anti-DNA antibody formation is not surprising in view of the finding that HGG suppresses polyclonal activation in vitro (40) and intravenous administration of HGG may interfere with T-B cell cooperation (41). Thus, even if HGG may nonspecifically downregulate the immune response, this further supports its choice as a tolerogenic carrier molecule.

The spontaneous production of anti-DNA antibody by cultured lymphoid cells from people with SLE provides an in vitro model to test the tolerogenicity of DNA fragments of various sizes linked to HGG. Further experiments are needed to determine whether the specificity of the antibody produced by lymphoid cells in vitro corresponds to that produced in the serum in vivo. This question bears on the issue of whether "generic" or "custom-made" tolerogens have to be constructed for the treatment of the disease.

Whether administration of oligonucleotides linked to HGG will influence the production not only of anti-DNA antibodies but also of other antibodies cross-reactive to this antigen is unknown. The specific suppression of anti-DNA antibodies by the induction of immunologic tolerance to DNA might not only allow examination of the role played by immune complexes containing nucleic acid but also that of immune complexes irrelevant to DNA in the pathogenesis of the disease. In conclusion, these data obtained in humans in vitro together with preliminary data obtained in $(\mathrm{NZB} \times \mathrm{NZW}) \mathrm{F} 1$ mice (42) suggest that the principles of tolerance can be applied to specifically modulate undesirable autoimmune responses.

\section{Acknowledgments}

We are grateful to David Bastian for his outstanding technical assistance and to Dr. F. D. Steinberg who generously provided blood samples from patients with SLE.

This work was supported by National Institutes of Health grants AR-36830 and AI-21066, and in part by a grant from the Central Laboratory, Red Cross Foundation, Bern, Switzerland.

\section{References}

1. Hahn, B. H. 1980. Systemic lupus erythematosus. In Clinical Immunology. C. W. Parker, editor. W. B. Saunders Co., Philadelphia. 583-631.

2. Tan, E. M. 1982. Autoantibodies to nuclear antigens (ANA): their immunobiology and medicine. Adv. Immunol. 33:167-240.

3. Smolen, J. S., and A. D. Steinberg. 1982. Disorders of immune regulation. In Pathophysiology of Human Immunologic Disorders. J. Twomey, editor. Urban and Schwarzenberg Publications, Baltimore. 173.

4. Eilat, D. 1985. Crossreactions of anti-DNA antibodies and the central dogma of lupus nephritis. Immunol. Today. 6:123-127.

5. Schwartz, R. S., and B. D. Stollar. 1985. Origins of anti-DNA autoantibodies. J. Clin. Invest. 75:321-323.

6. Schoenfeld, Y., J. Rauch, H. Massicotte, S. K. Datta, J. AndréSchwartz, B. D. Stollar, and R. S. Schwartz. 1983. Polyspecificity of monoclonal lupus autoantibodies produced by human-human hybridomas. N. Engl. J. Med. 308:414-420.

7. Lafer, E. M., J. Rauch, C. Andrzejewski, D. Mudd, B. C. Furie, B. Furie, R. S. Schwartz, and B. D. Stollar. 1981. Polyspecific mono- 
clonal lupus autoantibodies reactive with both polynucleotides and phospholipids. J. Exp. Med. 153:897-909.

8. Rubin, R. L., R. S. Balderas, E. M. Tan, F. J. Dixon, and A. N. Theofilopoulos. 1984. Multiple autoantigen binding capabilities of mouse monoclonal antibodies selected for rheumatoid factor activity. J. Exp. Med. 159:1429-1440.

9. André-Schwartz, J., S. K. Datta, Y. Shoenfeld, D. A. Isenberg, B. D. Stollar, and R. S. Schwartz. 1984. Binding of cytoskeletal proteins by monoclonal anti-DNA lupus autoantibodies. 1984. Clin. Immunol. Immunopathol. 31:261-271.

10. Jacob L., F. Tron, J. F. Bach, and D. Louvard. A monoclonal anti-DNA antibody also binds to cell-surface protein(s). 1984. Proc. Natl. Acad. Sci. USA. 81:3843-3845.

11. Carroll, P., D. Stafford, R. S. Schwartz, and B. D. Stollar. 1985. Murine monoclonal anti-DNA autoantibodies bind to endogenous bacteria. J. Immunol. 135:1086-1090.

12. Pisetsky, D. S., S. O. Hoch, C. L. Klatt, M. A. O'Donnell, and J. D. Keene. 1985. Specificity and idiotypic analysis of a monoclonal anti-Sm antibody with anti-DNA activity. J. Immunol. 135:40804085.

13. Rauch, J. H., D. Teiteigaum, B. D. Stollar, and R. S. Schwartz. 1984. Monoclonal anti-cardiolipin antibodies bind to DNA. Eur. $J$ Immunol. 14:529-534.

14. Pincus, T., P. H. Schur, J. A. Rose, J. L. Decker, and N. Talal. 1969. Measurement of serum DNA-binding activity in systemic lupus erythematosus. $N$. Engl. J. Med. 281:701-705.

15. Miniter, M. F., B. D. Stollar, and V. Agnello. 1979. Reassessment of the clinical significance of native DNA antibodies in systemic lupus erythematosus. Arthritis Rheum. 22:959-968.

16. Miller, T. E., R. G. Lahita, V. J. Zarro, J. MacWilliam, and D. Koffler. 1981. Clinical significance of anti-double-stranded DNA antibodies detected by a solid phase enzyme immunoassay. Arthritis Rheum. 24:602-610.

17. Jacob, L., M. A. Lety, D. Choquette, J. P. Viard, F. Jacob, D. Louvard, and J. F. Bach. 1987. Presence of antibodies against a cell surface protein, crossreactive with DNA in systemic lupus erythrematosus: a marker of the disease. Proc. Natl. Acad. Sci. USA. 84:29562959.

18. Tan, E. M., P. H. Schur, R. I. Carr, and H. G. Kunkel. 1966 Deoxyribonucleic acid (DNA) and antibodies to DNA in the serum of patients with systemic lupus erythematosus. J. Clin. Invest. 45:17321740.

19. Rothfield, N. F., and B. D. Stollar. 1967. The relation of immunoglobulin class, pattern of antinuclear antibody, and complementfixing antibodies to DNA in sera from patients with systemic lupus erythematosus. J. Clin. Invest. 46:1785-1794.

20. Lambert, P. H., and F. J. Dixon. 1968. Pathogenesis of the glomerulonephritis of the NZW/W mice. J. Exp. Med. 127:507-522.

21. Koffler, D., P. H. Schur, and H. G. Kunkel. 1967. Immunological studies concerning the nephritis of systemic lupus erythematosus. J. Exp. Med. 126:607-624.

22. Borel, H., T. Sasaki, B. D. Stollar, and Y. Borel. 1984. Conjugation of DNA fragments to protein carriers by gluteraldehyde: immunogenicity of oligonucleotide-hemocyanin conjugates. J. Immunol. Methods. 62:289-302.

23. Bastian, D., H. Borel, T. Sasaki, A. D. Steinberg, and Y. Borel. 1985. Immune response to nucleic acid antigens and native DNA by human peripheral blood lymphocytes in vitro. J. Immunol. 135:17721777.

24. Borel, Y., R. M. Lewis, and B. D. Stollar. 1973. Prevention of murine lupus nephritis by carrier-dependent induction of immunologic tolerance to denatured DNA. Science (Wash. DC). 182:76-78.

25. Tan, E. M., A. S. Cohen, J. F. Fries, A. T. Masi, D. J. McShane,
N. F. Rothfield, and J. G. Schaller. 1982. Revised criteria for the classification of systemic lupus erythematosus. Arthritis Rheum. 25:1271-1277.

26. Morimoto, C. A., A. Steinberg, S. F. Schlossman, and Y. Borel. 1983. In vitro nucleoside specific immune response by lymphocytes from systemic lupus erythematosus. J. Clin. Invest. 71:1402-1409.

27. Papalian, M., E. Lafer, R. Wong, and B. D. Stollar. 1980. Reaction of systemic lupus erythematosus antinative DNA with native DNA fragments from 20 to 1,200 base pairs. J. Clin. Invest. 65:469477.

28. Stollar, B. D., and Y. Borel. 1976. Nucleoside specificity in the carrier IgG-dependent induction of tolerance. J. Immunol. 117:13081313.

29. Stollar, B. D., and Y. Borel. 1977. Nucleoside specific tolerance suppresses anti-nucleoside antibody-forming cells. Nature (Lond.). 267:158-160.

30. Ando, D. G., E. E. Sercarz, and B. H. Hahn. 1987. Mechanisms of $T$ and $B$ cell collaboration in the in vitro production of anti-DNA antibodies in the NZB/NZW $F_{1}$ murine SLE model. J. Immunol. 138:3185-3190.

31. Sano, H., and C. Morimoto. 1981. Isolation of DNA from DNA/antiDNA antibody immune complexes in systemic lupus erythematosus. J. Immunol. 126:538-539.

32. Winfield, J. B., I. Faiferman, and D. Koffler. 1977. Avidity of anti-DNA antibodies in serum and IgG glomerular eluates from patient with systemic lupus erythematosus: association of high avidity antinative DNA antibody with glomerulonephritis. J. Clin. Invest. 59:90-96.

33. Emlen, W., D. S. Pisetsky, and R. P. Taylor. 1986. Antibodies to DNA: a perspective. Arthritis Rheum. 29:1417-1426.

34. Takashi, T., J. Koide, O. Hosono, K. Amano, M. Homma, Y. Masuho, C. Morimoto, M. Takano, and T. Abe. 1986. DNA-Daunorubicin complexes specifically suppress in vitro spontaneous antiDNA antibody production in lymphocytes of patients with systemic lupus erythematosus. Arthritis Rheum. 29:1216-1222.

35. Sasaki, T., T. Muryor, O. Takai, E. Tamate, Y. Ono, Y. Koide, N. Ishida, and K. Yoshinaga. 1986. Selective elimination of anti-DNA antibody-producing cells by antiidiotypic antibody conjugated neocarzinostatin. J. Clin. Invest. 77:1382-1386.

36. Eshhar, Z., B. Benacerraf, and D. H. Katz. 1975. Induction of tolerance to nucleic acid determinants by administration of a complex of nucleoside D-glutamic acid and D-lysine (D-G-L). J. Immunol. 114:872-876.

37. Parker, L. P., B. H. Hahn, and C. K. Osterland. 1974. Modification of NZB/NZW)F $F_{1}$ autoimmune disease by development of tolerance to DNA. J. Immunol. 113:392-394.

38. Geha, R. S., L. Fruchter, and Y. Borel. 1980. Hapten-specific T-cell unresponsiveness induced by benzylpenicilloyl antologous gammaglobulin conjugates in human lymphocytes in vitro. J. Clin. Invest. 65:1509-1514.

39. Morimoto, C., and Y. Borel. 1983. Hapten-specific carrier-dependent tolerance induction in man in vitro. Cell. Immunol. 82:415421.

40. Stohl, W. 1986. Cellular mechanisms in the in vitro inhibition of pokeweed mitogen induced $B$ cell differentiation by immunoglobulin for intravenous use. J. Immunol. 36:4407-4413.

41. Leung, D. Y. M., J. C. Burns, J. Newburger, and R. S. Geha. 1987. Reversal of lymphocyte activation in vivo in the Kawasaki syndrome by intravenous gammaglobulin. J. Clin. Invest. 79:468-472.

42. Borel, H., D. Bastian, B. Cooper, and Y. Borel. 1986. A possible new therapy of systemic lupus erythematosus. Ann. NY Acad. Sci. 475:296-306. 